Magnus Ronn | LM Tucker | Ron Dulaney Jr. Sinclair, Mousazadeh, Safarzadeh | James Shraiky Marci Uihlein | Tang, Anderson, Aksamija, Hodge

\section{The prequalified competition - how are architects appointed to invited architectural competitions?}

\author{
Magnus Rönn, The School of Architecture and the Built \\ Environment \\ The Royal Institute of Technology, Stockholm, Sweden
}

\section{INTRODUCTION}

Prequalification is a selection process used by public organizers for competitions with a limited number of participants. The organizers begin the process by issuing an invitation describing the general tasks of the competition, the evaluation criteria on which the choice of candidates will be based, and the documents to be included with the application. Architect firms wishing to partake in the competition respond to the invitation by sending in an application. A group of experts at the organizer examine the applications and select candidates for the competition. Usually three to six architect firms/teams are selected. This is a short description of prequalification for invited competitions organized by municipal and governmental organizers in Sweden.

Prequalification is a meeting between two parties: the organizers and the interested architect firms. How that meeting takes place can be described either from the organizer's point of view or the architect firm's perspectives. In this study I review prequalification from the standpoint of how public organizers select architect firms for invited architectural competitions.

There are surprisingly few studies, which focus on how architects are chosen for invited competitions. Prequalification has been studied in Holland and Denmark. In her study Deciding about Design Quality, Leentje Volker (2010) recounts how public developers in Holland procure architectural services. She studies both the obstacles and the possible success factors in procurement. There is a great deal of dissatisfaction among architects in Holland about the bureaucratic and costly application requirements demanded by public procurers (Kroese, Meijer \& Visscher, 2009). Volker and Lauche (2008) note that the evaluation of architects for competitions and the judging of competition proposals resemble each other, even if the criteria differ. Architecture criticism seems to be as a way to understand the selection producers in competitions (Benedict, 2007; Rönn, 2012).

The Danish survey about prequalification in architectural competitions was made at the Copenhagen School of Economics by Kristian Kreiner and Merete Gorm 2008 and 2009. The study from 2008 describes the perspective and experience of promoters. This survey is based on a questionnaire, which was answered by 98 informants. Of these, $60 \%$ 
were public promoters and $40 \%$ private. The structure of the Danish inquiry on prequalification differed from mine on two essential points. I seek information about prequalification using a combination of open questions in an interview guide and the review of documents from strategically selected public organizers. The second difference concerns promoters. The respondents in the Danish study were both private and public firms/companies. I have investigated architectural competitions arranged by municipal and governmental organizers. My informants are public arrangers and they must select firms/teams in accordance with the Swedish Public Procurement Act. This law is based on a European regulation (Directive 2004/18/EC). We do have in common though, that we studied contemporary competitions in relation to the organizers' choice of architect firms. I contribute to the field of knowledge with new empiricism.

\section{Aim and Research Questions}

This article is part of a study about how public organizers in Sweden select architect firms for invited competitions. Of central interest to the research are the invitation, application and selection of candidates. $A$ basic assumption behind the study is that prequalification contains a series of choices on behalf of the organizer and the architect firms. The parties are dependent upon each other, even if their influence is unevenly distributed and varies over time. The organizer initiates the process by extending invitations for prequalification. Architect firms who wish to participate in the competition respond by sending in their application. That is an active choice, which assumes that there are interested architect firms. Candidates who refrain from applying make a choice which might depend on lack of interest, lack of resources or the impression that the chances of succeeding are too low. Architect firms with incomplete or weak applications are eliminated by the organizer and do not proceed to the competition.

The study assumes that the organizers select candidates for the competition who have attractive professional profiles. They are the architect firms/teams, which the organizer's reviewer deem most suitable to the competition task. Either the organizer tries to find a suitable mix of candidates with varied profiles or applicants are chosen on their individual merits. Since there are many more applications than number of places in invited competitions the organizer must make an evaluated selection. Some candidates must be seen as better than others. Here lies the study's fundamental research problem. My intention is to highlight prequalification with the support of the following five questions:

-Why are invited competitions organized?

- Who drew up the invitation and formulated the application requirements and criteria for evaluation?

- Did the architect firm meet the organizer's need for information?

- How was the review/judging organized and carried through?

-What are the organizer's experiences from choosing candidates for the competition?

\section{Theory and method}

The study is based on a theoretical reference frame, which includes inventory, case studies, document review and interviews. The collection and processing of data is based on:

- Inventory: The study began with an inventory of the Swedish Architects Association's home page for competitions. Competitions approved by the association were listed here. The inventory was limited to public competitions for the period 2007-2009. Mapping was used to choose competitions that highlighted important traits of prequalification.

- Case Studies: Using the inventory I examined 10 competitions. Five municipal competitions and five governmental competitions were chosen as case studies. From the Swedish Architects Association's home page I downloaded the following documents from the competitions: Competition program, competition proposal (site plans, facades, sections, illustrations and descriptive text) and jury statement (www.arkitekt.se/tavlingar).

- Document review: To access additional competition documents the person who represented the organizer was contacted. I made a written request for minutes from the meetings, background material for the decision, protocol and the invitation to prequalification. These documents show the formal side of the process. The documents have been used as background material for case studies, for identifying the organizer's informants and for the interview guide.

- Interview of key persons: Information about how the organizer experienced the selection of candidates for the competition was given by key persons from five organizers. These were persons who played an active role in prequalification as reviewers of applications submitted by the architect firms. The interviews were based on the interview guide with open questions about the background of architect competitions, competition form, invitation, judging process and reviewers' experiences from prequalification (Kvale, 1997). The informants wrote the answers to the questions directly in the interview guide. The answers communicate personal experiences and give a deeper picture of the selection from the organizer's point of view.

\section{Selection of cases}

The search for cases began with a review of The Swedish Association of Architects' homepage. There were 29 competitions shown for the period 2007-2009 approved by the association and carried out in Sweden.

\begin{tabular}{|l|l|l|l|}
\hline Competition type & Governmental & Municipal & Private \\
\hline Open competition: 9 & 1 & 7 & 1 \\
\hline Invited competition: 20 & 6 & 14 & \\
\hline Total: 29 & 7 & 21 & 1 \\
\hline
\end{tabular}

Table 1: Number of competitions 2007-2009 at the homepage. 
There are 20 invited competitions during that period 2007-2009 and ten have been chosen for case studies. Five organized by governmental clients and five arranged by municipals promoters. The five cases governmental competitions are:

- 2009 competition for an exhibition building (visitor's centre) in a national park (Laponia)

- 2008 competition for an exhibition building (visitor's centre) at Lake Vänern (Victoria House)

- 2007 competition for an exhibition building (visitor's centre) at Lake Tåkern

- 2007 competition for an exhibition building (visitor's centre) for nature reserve (Stendörren)

- 2007 competition for a new entrance to national park (Skuleskogen)

The following municipal competitions are:

- 2009 competition for Stora Torget (Main Square) in Visby town

- 2009 competition for housing at Västra Kajen, Jönköping town

- 2008 competition for Cultural Centre in Vaxholm town

- 2007 competition for exhibition building (visitor's centre) for wetlands in

Kristianstad

- 2007 competition for a new Music \& Theatre in Jönköping town

\section{Informants}

There are totally 19 experts representing three municipal and two governmental organizers who described their experiences in the interview guide. The response was very good. 19 of the 21 persons who participated in choosing the architect firms for the five organizers answered the questions in the interview guide. The informants are an experienced group of referees. Their professional profiles may be summarized as follows:

- Gender: 9 women and 10 men.

- Age: 13 of 19 informants were over 50 year.

- Number of years in profession: 13 of 19 had at least 20 years' experience. Of those, 7 had more than 31 years of experience.

- Professional background: 8 informants are architects, 3 are engineers, 2 are biologists, and 1 is a planner. The remaining 6 answered "other" professional fields.

-Work: 8 informants work with architecture and town planning. They are architects. 7 work as project leaders and purchasers of services. They are engineers, biologists, and persons with "other" capacities. 3 have management control as their main occupation. One informant replied "other".

There is an equal division of informants with regard to gender. The majority are over 50 . One reviewer is under 30 . The other five are 30-49 years. Most have at least 20 years professional experience (13 of 19 informants). Architects make up the dominant group among informants. Project leaders and purchasers of services account for an almost equally large group. In short, the replies show that the persons reviewing the architects' applications for the organizer are an experienced group of people with all-round knowledge. Their professional merits are of an interdisciplinary nature with a base in architecture and the built environment as well as procurements. Thus, there are no grounds for questioning the competence of the reviewers.

\section{RESULT}

This section presents the opinions of the informants on prequalification. Their replies to the questions in the interview guides are discussed in five areas: competition form, invitation, need for information, judging process, and experience from selection of teams. The accounts contain some quotes from the interview guide. These quotations are used to give a more realistic picture of the reviewers' experiences. In this account I have made some minor language adjustments; abbreviations have been fully written out and everyday oral expressions have been transposed into written language. In this way I hope to convey the informants' replies to the reader in a more accurate way.

The report on the results begins with empirical data from prequalification. The ten competitions generated a total of 375 applications. Of these, 315 (84 \%) come from Swedish architect firms. The number of applications varies from 9 to 62 per competition. Altogether, 43 firms/teams (11\%) were invited to the competitions. The remainder ( $89 \%)$ was eliminated during prequalification. The organizers' chose 3 to 6 firms per competition. 38 of the 43 invited firms/teams ( $88 \%$ ) are Swedish. All of the winners in the 10 competitions are Swedish firms/teams.

One of the firms, which won first prize, Tham \& Videgård Hansson Arkitekter, was described by the organizers as "a young, creative firm with great architectural abilities" (Statement 2008-09-30). But this is a firm, which had already existed for 10 years at the time of the competition. The responsible architect was 40 years old. To be "young and creative" is a judgement that reflects a general opinion about a firm's profile, reputation or ability to renew itself rather than measurable criteria such as the number of years in the profession and age of the responsible architect. 4 out of 10 organizers have had "young and creative" as criteria for the selection of firm/team. However, organizers give no indication about how this ambition should be understood or reached in prequalification. A similar desire for renewal appears in the Danish study. $37 \%$ of promoters replied that they would like to have a "wild card" in the competitions (Kreiner and Gorm, 2008). The Danish Wild-card system has specific conditions for firms to meet to be on the list.

\section{Competition Form}

Prequalification is not an isolated activity for organizers but part of a planning process. As soon as the invitation to prequalification is made public via electronic data bases and home pages, competition is established as the work method for the building task. This decision is based on a need, an aesthetic ambition and preparations for a detailed 
development plan, which regulates how the site will be used. The competition is motivated because the building tasks are challenging and put high demands on the architectural quality. Some reviewers refer to this aesthetic ambition as the organizers' desire to create a profile building that stands apart from the ordinary. The building "should be an attraction in itself" as one project leader expressed it.

The interviews show that organizers have a very positive impression of competitions. Architectural competitions are seen as an experimental arena, which promotes the development of quality in a project. The reviewers' experience coincides with how the Swedish Association of Architects promotes their competition service on their homepage (www. arkitekt.se/tavlingar). The informers point out five reasons. Organizers use competitions to (a) identify new ideas and innovative proposals, (b) develop good solutions that meet high demands for architectural quality and function, (c) reflect openness towards the local community, as well as the interested parties, (d) negotiate qualified architectural services and (e) get away from the preconceived notions and traditions of the promoters.

Competitions appear to be an answer to the complex strategic aim of organizers. In spite of the fact that three of the winning competition proposals were not implemented, the reviewers are positive towards prequalification. One project leader disappointedly noted that the competitions were not well anchored politically since the municipality "did not go further after the winner was selected." Criticism against the competition form comes from only one experienced informant, who noted that invited competitions have a tendency to favour established and wellknown firms with good reputations in the field.

Even with the ambition to include someone from an untried firm it's hard to find out which one it should be. That may be a disadvantage with invited competitions: that certain firms become successful, get even better references and greater chances for invitations in an upward spiral where less-known firms have few chances of getting in.

Architect, interview 2011.

The fact that the informants are attracted to the competition as a work method does not explain the competition form. Why did the organizers choose competitions with limited participation? The answer is not so clear cut. Some reviewers see the invited competition as a compromise between great ambitions and limited economic resources. Two answers that shed light on this dilemma are:

(Organizers had) a positive attitude towards competition as a form of negotiating architectural services... Besides, this was a prestigious project... At the same time it was a rather small project with a rather strained economy. An invited competition with 5-6 participants was judged to be what the project could afford.

Architect, interview 2011.
Since, in spite of the attention, it is a small place in a small municipality, and also a small purse, we chose to have an invited competition with prequalification. That is because our resources both for judging and competition remuneration were limited. We thought that many firms would be interested and we would not have the personnel to handle an open competition.

Project leader, interview 2011.

According to the informants, another reason for choosing the competition form is that it reflects the general faith in competitions as a driving force for developing the quality of projects.

We civil servants, and afterwards politicians, realized the question had such great potential... (that) in the end an invited architectural competition was obvious. To juxtapose different proposals against each other to find the best solution. That is also the reason why we chose an invited competition with prequalification.

Architect, interview 2011.

Several informants maintain that the attitude of collaborators and contacts with the Swedish Association of Architects were crucial for choosing the competition form. "The invited competition was chosen on the advice of the Swedish Association of Architects", the project leader replied. The arrangers were several organizations and interested parties collaborated on the project. Thus government competitions presume that there is a wide range of support for the competition idea on the national, regional and local levels.

At an early stage the work group contacted the Swedish Association of Architects, which was the competition administrator during the work with the competition. It was decided that to get an outstanding building an invited competition would take place. The Swedish Environmental Protection Agency (Naturvårdsverket) chose the invited competition form as the procedure for the design of the new visitor's centre (Naturum). Client, interview 2011.

\section{Invitation}

In the invitation the organizer sets forth the general conditions, submission requirements and the criteria, which will be used as the basis for evaluating the applications from the architect firms. The information in the invitation determines the interest potential participants show in the competition. The general conditions in the invitation specify:

- competition form

- number of competitors

- language of the competition

- remuneration

The ten organizers in the study used invited project competitions. The aim of the competition is that it should result both in building suggestions 
with a high level of architectural quality and an architect firm to carry out the project. The winner is promised to get the assignment on condition that it is carried through by the client. The general terms are formulated in the same way. The invitation reflects the established praxis of the profession rather than strategic considerations in the planning process by the organizers. The conditions have been decided in consultation with the Swedish Association of Architects and after comparison with other similar competitions.

Four firms were considered appropriate for the project. (That) was decided in consultation with the Association of Swedish Architects. The choice of competition language was Swedish out of consideration for the local support for the project and the handling of the politically steered organization that the municipality is. The financial remuneration was decided in consultation with the Association of Swedish Architects. Planner, interview 2011.

It was the available competition budget and comparison... which determined the number of competitors. A remuneration of 12500 EURO was considered reasonable for a maximum of four charts and 5-6 competitors should give a broad enough scope for the assignment. Architect, interview 2011.

Generally, the informants pointed out that the invitation was drawn up in consultation with the Swedish Association of Architects. The choice of language was motivated by practical arguments. "Swedish was most natural for this type of competition" was a typical reply. The requirement facilitates checking out the references and future communication with the winner. The competition language limits the number of applications from foreign firms and results in the competition culture taking on a national character with a Nordic overtone. But that is not a problem for the organizers. The general conditions in the invitation are seen by the reviewers as a product of economy and the desire for a broad competition. The organizers' remuneration for the competing architect firms is $10000-20000$ EURO. The sum is considered "normal" for the task.

\section{Application requirements and criteria for evaluation}

The specific conditions in the invitation are a combination of "tough" must-requirements and "soft" criteria for evaluating a candidate's merits. Must-requirements are a sort of entrance ticket to the competition. The organizer specifies which documents the architect firms must include in their applications. Candidates who do not fulfill the requirements are immediately eliminated. Toughness lies in the measurable effects and apparent precision of the requirements (Sällström, 1980). Evaluation criteria have a completely different character and put the professional profile of the applicant in focus. There is softness in their evaluation role, the search for a suitable candidate. To use these criteria the organizer needs access to experienced persons with good judgment. The reviewer evaluates the design team's professional profile with regard to the competition task.

\section{Must-requirements}

The organizer uses the application requirements and criteria in the invitation to convey to the potential candidates how their applications will be examined. A certain number of must-requirements and criteria reappear all the time. Architect firms wishing to participate in competitions must send in applications, which meet the following requirements:

- Curriculum Vitae: CV for responsible architects, their education and professional qualifications for the competition assignment.

- Reference project: 3-5 reference projects relevant to the competition assignment. Usually 2 out of 3 projects should have been carried through.

- Personal references: Contact information for reference persons of the clients mentioned in the projects (promoters and entrepreneurs). - Project organization: A plan showing how the assignment should be carried out and how the necessary areas of knowledge/professions should be coordinated for the project.

- Quality system and environmental policy: Statement of the firm's internal quality system and environmental policy.

- Finances and taxes: Documentation of company's financial situation and taxes paid in. This information should not be more than two months old.

- Contact information for the company: Company's registration number including the name, telephone number and e-mail address of the contact person.

- Affidavit: An affidavit signed by the legal representative stating the firm has not filed for bankruptcy, is not under court administration or committed any grievous error in the practice of the profession.

Finally, the application should be signed by the firm's accredited persons and submitted on time. The document is an expression of administrative security, financial security and professional competence for the competition task. The project organization gives the client a preliminary idea about how the architect firms view the assignment. The demand for completed reference projects facilitates contact with promoters and entrepreneurs.

\section{Evaluative criteria}

Reviewers use soft evaluation criteria to judge the professional merits and references of the candidates. Again, a clear pattern appears. The same design criteria are found in the organizer's invitation. The suitability of an architect firm is examined considering:

- Architectural quality: How has the architect applied the concept of "good architecture" in the reference project?

- Creative ability: How has the architect developed innovative solutions to the architectural and functional problems of the reference project? 
- Collaboration: How has the architect cooperated with the client and the contractor on the reference project?

- Competence and resources: Does the competition team have the professional competence and the resources asked for to fulfill the assignment?

All organizers include these four evaluation criteria in the invitation. In some cases the organizer has completed the invitation with criteria about how the architect solved environmental aspects and accessibility in the reference project. The criteria have an open nature that is typical for architecture. By directing questions to the references given by the architect firm, the reviewers acquire knowledge about their professional qualifications and suitability for the assignment. The decision about who will be invited to participate in the competition evolves from a dialoguebased evaluation.

Municipal and government organizers have the same application requirements and evaluation criteria. However, the way in which the invitation is formed varies. Some arrangers have hired an external consultant for the task. Others have an in-house project leader, who drawn up the proposal for application requirements and evaluation criteria. But both methods have in common that the final versions were drawn up in consultation with the Swedish Association of Architects.

It was I who formulated the requirements, which were then approved... (by the organizer). We were also in contact with the competition secretary at the Association of Swedish Architects and their procurement department. My ambition was that as many procedures as possible would be the same as earlier invitations to prequalification...

Architect, interview 2011.

Many of the must-requirements were formalities... which the procurement officer provides. Requirements to show the suitability for the task through, for example, professional qualifications, availability of resources and routines for environmental guarantees are also... standard. Reference objects and projects were the most important and I remember we were very careful to give the minimum and maximum number... We (had) earlier experiences where interested architects sent in their entire portfolio instead of selecting the most suitable references. Architect, interview 2011.

The work group prepared the must-requirements and evaluation criteria... Together with the competition administrator they went through the competition invitation where it became evident that there should not be more must-requirements than necessary and that the most important was an assurance that the architects were not involved in any faulty financial situations and had the capacity to carry through the assignment. Other evaluation criteria discussed were among others experience..., environmental profile, and ability to create something exciting and innovative.

Client, interview 2011.

\section{Information needed}

According to the informants the invitation resulted in the required information from the architect firms. There was no need for further written documents. Nor was there any risk of additional bureaucracy and administrative expenses due to over-extensive demands for accounting. From the organizer's perspective the application requirements and evaluation criteria fulfilled their needs for information. The reviewers had access to all the documents they needed to identify suitable candidates for the task. The interview answers are clear on this point. It is only towards the end of the judging process, when there are just a handful of favorites remaining, that the reviewers required more information about the candidates and contacted the reference persons.

All firms were well-known and had excellent references. It was decided that further inquiries were not necessary.

Project leader, interview 2011

Generally, the applications furnished all the information we needed. The reference persons were contacted for the three chosen firms.

Architect, interview 2011

I thought that there was enough information in the applications... For the last five "finalists" the promoter's reference persons were contacted and the competitors were chosen taking these into consideration.

Project leader, interview 2011

References were checked; otherwise the reference project itself was used as a statement of how the firm related to a complex urban design assignment.

Architect, interview 2011

Thus far the picture is unanimous. But when the informants comment on how the applications should be evaluated the answers vary. There are two different viewpoints. Some reviewers think the evaluations should be based only on the applications themselves. Their arguments are:

We received the necessary reference material in the applications. We found it important to consider only the material the applicant decided to send in and the reference objects they chose in order to make an objective evaluation based on impartial grounds.

Planner, interview 2011

A somewhat opposite opinion is expressed by reviewers who believe the organizers could take into consideration other information when judging candidates.

A discussion arose about how our earlier knowledge of a firm should be weighed in the evaluations, or if we should be strictly limited to the material submitted. Inevitably our general knowledge about the firm influenced the evaluation.

Architect, interview 2011 
At the end of the prequalification the organizer sought additional information about the candidates from promoters and entrepreneurs. In this case, organizers asked the architect's clients about their personal experiences. This is an extra follow-up, which creates a feeling of security in an insecure situation.

We didn't make any study visit... On the other hand our telephone conversations with the clients/promoters were very fruifful. We found out if the planning went well, if the budget and time schedule were met and if the final result was good and functioned.

Project leader, interview 2011

The project leader contacted several architectural firms for additional information. We called the municipalities where the firms had completed projects. Myself I called...

Architect, interview 2011

Some documents in the candidates' applications are more important than others for the evaluation. The importance of the information varies. For example, an architect firm's professional profile is seen as key information by reviewers. Good reputations in the field, earlier experience in designing similar buildings, are references of extra high informative value. An illustrative answer is:

References were, as expected, most decisive. Both the choice of what one deemed to be "comparative objects" and how they were actually realized and described were important for the evaluation. Which persons should work with our project was also important.

Architect, interview 2011

\section{Judging process}

Candidates are selected in a judging process with two distinct phases, which follow one another in a fixed order. First, it is established if the must-requirements have been fulfilled. Then the professional merits of the candidates are investigated. The result is a judging process which changes focus from the review of documents based on "hard" musthave requirements to the evaluation of qualifications based on "soft" criteria (Sällström, 1980). Most architect firms have sound finances, administration, and references and submit complete applications. However, two competitions show a deviant pattern where many candidates were eliminated already in the initial stage. Apparently there are "strict" organizers with reviewers who make harder controls of applications than others. The "liberal" organizers allow all candidates who have sent in the required documents to proceed in the competition. In both cases, the end result is that $89 \%$ of the candidates are eliminated. The difference lies in how the organizer examines the contents of the documents and interprets the applicants' suitability for the competition task. The majority of organizers prefer to delay the elimination in order to benefit from the architectural critique evaluation of the candidates' professional references.
It takes time to choose architect firms for competitions. The reviewers usually need to meet several times. The number of meetings varies from two well-prepared whole day meetings with review groups to eight meetings. The process has a collective nature. There is a group of reviewers from the organizer, usually three to six persons, who nominate candidates. The choice is characterized by consensus. A decision develops. With little difficulty the reviewers have been able to agree upon which architect firms are most suitable for the competition. The judging is managed by the organizer's wish to find competent design teams for the upcoming assignment. Some candidates stand out more than others. How is the ranking made?

For all organizers the first stage of the judging procedure is marked by controls. It is in the second phase of the evaluation that differences appear. The reviewers use three methods to identify suitable candidates. Architectural critique evaluation is used afterwards to justify the choice. The informants describe the first method as a breakdown of applications into different categories. The reviewers are looking for qualitative differences between applications to explain the ranking. The candidates are categorized as "very interesting", "interesting", or "uninteresting". Alternatively, architect firms are categorized as "young firms with an exciting project", "qualified architects with good reputations" or "wellknown firms with high architectural competence". A mix of candidates is then selected. The second method involves the reviewer recognizing the subjective character of the evaluation and choosing firms with an attractive professional profile. Design, references and expectations are coordinated into a whole assessment. The reviewers make a balance sheet of the desired qualities. In this case, the professional experience and good judgment of the reviewers gives a sense of security to the organizers. The third method involves pinpointing a rational ground for the selection. Here reviewers draw up tables and give quantitative numerical values to the applications. The points are based on the evaluation criteria in the invitation. By means of scoring some architect firms will appear to have more merits than others, which both motivate and legitimize the choice.

Reviewers who seek qualitative differences describe the evaluation process as the progressive elimination of candidates. In the end only the favorites remain. This method of selecting architect firms is described as follows:

First a rough elimination was made by a few representatives for the work group. Applications, which did not fulfill the must-requirements were eliminated... and also those which were judged to be less qualified, based on the competence references given by the office. This was followed by screening based on the given competence and reference object. The group's judgment was rather unanimous in most cases; discussions only arose over a few firms.

Project leader, interview 2011 
The judging group had 3-4 meetings where we sat for a rather long time and went through the applications. I recall that at the first meeting we divided the applications into four groups (best-poorest). The rest of the meeting was devoted to passing the applications around among these four groups until there were five applications remaining...

Architect, interview 2011

Reviewers who focus on the subjective nature of the selection rely on their professional experience and ability to see the qualities in the applications. The fact that evaluations are subjective is not a hinder but rather a "necessary" consequence of the task. Some candidates must be pointed out as being better than others. Knowledge, consensus and coordination of individual judgments in the evaluation process become a guarantee for a good end result.

The work group met and selected those who should continue to the invited competition. We individually rated the documents and made our own personal judgments. When we later compiled them it turned out that the members of the work group had amazingly similar opinions about the selection; there were only one or two proposals where there was a little discussion, but it was surprisingly simple and easy to agree upon who should continue.

Client, interview 2011

Reviewers who look for a rational reason for their choice of architect firms score the applications. The evaluation criteria in the invitation are given a numerical value, usually $1-5$ points. The candidates who fulfill the mustrequirements are scored according to how their applications describe (a) architectural ability, (b) competence and (c) experience and resources for the task. The final selection of architect firms for the competition is made from the candidates with the highest grades. Reviewers who used this model say the following:

We drew up a form, which was gradually filled in as the evaluations took place. There were clear instructions as to how the evaluations should be made for the respective evaluation criteria. Competence and experience were relatively easy to grade fairly...Architectonic expression was more difficult since it is a relatively subjective evaluation; here the various group members had to think based on their own professions. In the end we were wholly in agreement anyway about who should continue.

Project leader, interview 2011

The first check was just to go through all the applications received. After that we began to... score and further sort them out. The process was intense and we met many times so as to agree in the end.

Architect, interview 2011

\section{Organizer's experience}

The review group is made up of three to six persons competent in architecture and urban design, project management and procurement.
Some organizers have completed the group with persons representing the planned activities on the premises. Sometimes politicians are included. The group's composition reflects the competition's interdisciplinary tasks. One or two members from the review group continued to participate in the competitions but now as representatives for the organizer on the competition jury. In this way experience from choosing the candidates is passed on to the jury's quality evaluation of the competition proposals.

The informants project a positive image of prequalification. The encounter with the application documents is characterized by curiosity and expectation. The reviewers have been able to nominate an architect firm/team for the competition without any complicated negotiations. They describe the evaluation of the candidates' professional merits as a difficult, pleasant and instructive task. To choose architects for competitions is seen as a "wicked problem" (Churchman, 1967) in a future-oriented context, which holds the promise of an exciting sequel. This is how the informants described their experiences:

I am not used to architectural competitions. But compared with the procurements I do in other areas there were unexpectedly many applications.

Project manager, interview 2011

I thought there would be more complicated rounds, but with support and very good information about the work procedures I felt very comfortable in this context.

Client, interview 2011

Through the years I have only participated in a handful of similar tasks. It was interesting and instructive. Prequalification is not regulated by the LOU (Law on Public Procurement) to the same extent as other traditional contract building procurements.

Project manager, interview 2011

It was the first time I participated in work with an architectural competition and it was a positive experience. The judging group, jury and cooperation with the Swedish Association of Architects worked very well... Then of course it is a shame that the project has not yet been carried out, but we are hoping.

Architect, interview 2011

I have myself partaken in many competitions, won some or was rewarded, but this was the first time I joined in choosing the participants for an invited competition.

Architect, interview 2011

This was the first time I participated in prequalification. (I) previously took part as a competition secretary in an open competition and have been a jury member.

Architect, interview 2011 
Since the informants describe prequalification as such a good experience it raises the question as to why competitions are not used more frequently by municipal and government promoters. In spite of the fact that the reviewers are accomplished experts with long professional experience in architecture and urban design they have only participated in prequalification a few times. There is no criticism in the interviews either that could explain the limited use of competitions by organizers. On the contrary, even for organizers where the planning process stopped after the jury appointed a winner, there was a positive image of prequalification.

Only 3 out of 19 informants had negative comments about the competition process. One of them is an experienced architect who participated in several competitions and noted it was difficult for the review group to find an untried architect firm for the competition task. The criticism stems from the idea that invited competitions tend to favor established architect offices, which makes it difficult for new firms and young architects to be chosen. That, on the other hand, is the result of the organizer's requirements set forth in the invitation. The second informant was disappointed that the architectonic quality of the design proposal in the competition was not as high as expected. The third informant complained about the lack of political support, which resulted in the competition ending after the winner was appointed. But these voices are exceptions. Most people have only good experiences of prequalification. Several reviewers noted with surprise the wide interest shown by architectural firms in Europe. Since all of the organizers required Swedish as the competition language these applications were seen as a pleasant surprise.

\section{CONCLUSIONS AND DISCUSSIONS}

There are two fundamental principles municipal and governmental organizers may use for steering the competition process: ex-ante and expost. Ex-ante means that organizers try to control the competition process "ahead of time" through the competition task, the competition conditions and the choice of competing architect firms. Central to this steering is the invitation to prequalification. Ex-post means that the competition is steered "afterwards" by the design and the jury's assessment of the competition proposals. I am trying to understand how this steering "ahead of time" works. That is why I am interested in prequalification. My aim with this study was to investigate how prequalification appears from the organizer's point of view. I have done this by investigating experiences from selected architectural firms.

The study has two limitations, which should be commented upon before the conclusions are drawn. The first limitation concerns the perspective in the study. There are two parties participating in prequalification, each with their own point of departure. This study focuses only on the organizer's viewpoint. The other limitation is in the selection of informants. I have looked for reviewers with first-hand experience of prequalification. Informants judge their own actions and are pleased with the results. It can be assumed that their positive opinion about the competition influences how they describe prequalification in the interview guide. The replies from reviewers should be considered in the light of this prior attitude towards competitions as an arena for quality development in architecture and urban design.

The answers on the research questions in the study may be summarized in five parts:

- Competition: The most important reason for organizers choosing competition as a work form is that the task is seen as complicated and the project is aimed at high-quality architecture. The importance of the site generates aesthetic ambitions for the organizer. Competitions are the exception in daily practice and reserved for some especially important projects for municipal and government promoters. The competition form - invited project competition - is described by the informants as a compromise between great ambitions and limited resources. Advice from the Association of Swedish Architects has had significant influence on the decision. Municipal and government promoters perceive the choice of competition form as a practical question rather than a strategic consideration.

- Invitation: The organizer's invitation evolves during negotiations. The background material is compiled by external consultants and internal project managers with experience in purchasers of services. In both cases, the final draft of the invitation is made in consultation with the Swedish Association of Architects. The general regulations for competitions as well as the application requirements and evaluation criteria of the architectural firms are part of a professional praxis, which explains why invitations look so similar in the cases. A reviewer noted that the requirements in the invitation hinder renewal in the competition system. Candidates, who lack reference projects that have been carried out, relevant to the assignment, are eliminated. In spite of Swedish being the required language of the competition, $16 \%$ of the applications are from foreign architect firms. A possible explanation is that architects work in a European market and get to know about competitions via electronic negotiating systems and home pages. Another explanation is that there are Swedish-speaking architects in European firms.

- Need for information: Prequalification fulfills the organizers' need for information. The replies from architectural firms give the reviewers a good picture of the candidates' professional profiles and merits for the task. It is only when making the final choice of candidates that the reviewers need additional information and contact the reference persons. At this point, it is the developers and entrepreneurs experience of the firm that the organizer tries to investigate through dialogue with the architects' employers. The final selection is based on a combination of information in the way of written documents, descriptions and images of the reference project (drawings, illustrations, facades and plans) and oral information from the reference persons. 
-Judging process: The organizers select candidates using a judging process, which has two typical phases. The first phase is the control of the application for the must-requirements in the invitation and is followed by a second evaluation phase. The second phase has a succession of steps based on the criteria in the invitation and the classification of the applicants' professional profile. The judging process moves from the "hard" must-requirements to the evaluation of the candidates based on "soft" criteria. The process usually requires three to four meetings. A group of reviewers competent in architecture, urban design, project management and procurement of services selects the appropriate candidates. The reviewers use three methods to identify three to six firms/ teams for the competition task. The first method is ranking according to the qualitative differences among the applicants. The candidates are divided into groups according to their professional profile and how interesting they appear to the organizer. The second method affirms the subjective moment in the selection. Reviewers choose the candidates they like after a collective appraisal of their merits, references and their professional reputations. The third method is a search for a rational base for the selection. In this case the reviewers set up tables and score the candidates. The firms with the most points are invited to the competition. Architectural critique is used by all organizers to justify the choices.

-Experience from the selection of candidates: The informants relate two important experiences from prequalification. First, the selection of candidates is described in positive terms. It was challenging, exciting, educational and difficult, but enjoyable. Several reviewers were pleasantly surprised by the number of applications, which is interpreted as a sign of significant interest on the part of architect firms. Second, the response shows that the informants, despite long experience working with architecture and urban design, had only participated in a few cases of prequalification. For many it was the first time. Competitions are a one-time event, a work method only used for unique projects with extra high demands for architectural quality. The low competition frequency is in sharp contrast with the reviewers' good experience of prequalification. Possible explanations for so few competitions being arranged are the lack of resources in the form of time, knowledge and money. Planning takes time, competent persons are needed and finances are necessary to administrate the competition process, and to remunerate the competing firms and external jury members. Other factors which could be considered as limiting the competition is the conservative effect of the traditional planning process, pressed time schedules, and an unwillingness to be steered by competition regulations. Further, the lack of architectonic ambitions on the part of urban planners, consultants, entrepreneurs and developers contributes to architectural competitions being viewed as unnecessary. But the positive experiences from prequalification still remain.

\section{References}

Benedikt, M., 2007. Introduction in Sanders (Ed) Judging Architectural Value. Minneapolis: University of Minnesota Press.

Churchman, C. W., 1967. Wicked problems. Management Science, 14, No. 4.

European public procurement legislation and architectural service: Recommendation and guidelines for transposition to national law. (2005) ACE. Brussels: Architects Council of Europe.

Kreiner, K. and Gorm, M., 2008. Prekvalificering till arkitektkonkurrencer i Danmark. Del 1: Byggherens perspektiv of erfaringer, Center for ledelse i byggeriget: Arbetspaper. (Working paper)

Kreiner, K. and Gorm, M., 2009. Prekvalificering till arkitektkonkurrencer i Danmark. Del 2: Arkitekternes perspektiv of erfaringer, Center for ledelse i byggeriget: Arbetspaper. (Working paper)

Kroese, R., Meijer, F. and Visscher, H., 2009. European Directive for tendering architectural services; a too strict interpretation by Dutch Local Authorities? Available 2011-10-10: http://www.rics.org/site/download_ feed.aspx?filelD=5038\&fileExtension=PDF

Lag om offentlig upphandling, 2007:1091. (2007) Tillgänglig 2011-07-10: http://www. notisum. se/rnp/sls/lag/20071092.HTM

Positions on the 2004 public procurement directive (2004) EFCA. Brussels: Federation of Engineering Consultancy Associations.

Rönn, M., 2011. Den prekvalificerade tävlingen - hur utses arkitekter till inbjudna arkitekttävlingar? TRITA-ARK-Forskningspublikationer 2011:1, Stockholm: KTH

Rönn, M., 2012. A theory for assessing quality in Architectural competitions, Nordic Journal of Architectural Research, No 1. Rönn, M., Forthcoming. "A theory for assessing quality in Architectural competitions", Nordic Journal of Architectural Research, No 1 (in Press)

Svensson, C., 2008. Architectural competitions, the art of finding a winner, Stockholm: TRITA-ARK-Akademisk avhandling 2008:3, KTH.

Svensson, C., 2010. "Speaking of Architecture: A Study of the Jury's Assessment in an invited Competition" in Andersson, Rönn and Kazemian (Eds) The Architectural Competition: Research inquiries and Experiences. Latvia: Axl Book.

Sällström, P., 1980. Mjukdata i planeringsprocessen. Stockholm: Byggforskningsrådet, Rapport R74:1980

Volker, L., 2010. Deciding about Design Quality. Value judgements and decision making in the selection of architects by public clients under European tendering regulations. Leiden: Sidestone Press.

Volker, L., 2010. Design a design competition: the client perspective. Faculty of Architecture, Delft University of Technology. Paper presented at the conference Design \& Complexity, Montréal, 7-9 July 2010. Available 2011-07-05:

www.designresearchsociety.org/docs-procs/DRS2010/PDF/125.pdf

Volker, L. and Lauche, K., 2008. Decision making during a tendering procedure: case studies of restricted European tenders in architecture. 
In Dainty (Ed) Procs 24th Annual ARCOM Conference, 1-3 September 2008, Cardiff, UK, Association of Researchers in Construction Management.

Homepages

Swedish Association of Architects, Implemented competitions; Competition briefs, Design proposals and Jury Reports, Available 201112-30:

www.arkitekt.se/tavlingar/dokumentation

European Parliament and Council, Directive 2004/18/EC. Available 2011-12-30 http://eur-lex.europa.eu/LexUriServ/LexUriServ. do?uri=CELEX:32004L0018:SV:HTML

Informants

Interview Persons in alphabetical order:

Anonymous informant, architect / building design

Anonymous informant, another profession/position

Anonymous informants, engineer / project manager

Anonymous informants, procurement / client represent

Anders Bergquist, project manager

Anders Siversson, planner / urban design

Ann-Sofi Lindskog, architect / project management

Bernt Wennström, project manager

Cajsa Rydén, architect / building design

Carin Johanson, architect / urban design

Gillis Åström, engineer / client represent

Jan-Inge Tobiasson, procurement / client represent

Jonas Berglund, architect / urban design

Kristina Dunker, architect / urban design

Marie Björklund, procurement / project manager

Roland Karlsson, engineer /client represent

Roni Wallin, architect / building design

Susanne Edén, architect / urban design

Sven-Erik Magnusson, coordinator 